\title{
A Short Circuit of Reading: Red Dragon as Anti- Theory
}

\author{
Fabio Akcelrud Durão
}

Even if the transition from literary theory to Theory tout court has taken place mainly through the explosion of the Work and the consolidation of the text, extreme mainstream culture still remains an elusive theoretical object, challenging interpretation and evading judgment. The main reason for this lies in the peculiar force-field underlying it as a whole, for real mainstream culture, the moving totality of those artifacts that do not evince any pretence at originality or difference, is both too poor and too rich. Too poor, because mainstream symbolic forms are heteronomously produced. They do not follow, that is, their own internal logic, the rules of their own immanence, but are composed of, or fitted into, pre-conceived semiotic syntagms or narrative bricks (as car pursuits or redemptive kisses in film or the instrumental introduction to songs in music). In opposition to strictly classical works, as in Mozart for instance, where formulaic elements abound, the end-result of mainstream texts is not individuation but something closer to a patchwork that is structured by a regulating idea. The latter may consist of the sheer recycling of old stereotypes in different combinations, or it may, instead, offer one individual representation supposed to be new (to take another example from film: a black vampire fighting for the humans in Blade). Theodor Adorno, in a brilliant insight, compared socially constructed, mainstream heteronomy to Kant's schematism, a machine or framework mediating the very shape of perception and concepts for the subject, including its self-image ("The Schema of Mass Culture" 61-97). Unlike in Kant,

Fabio Akcelrud Durão is a professor of American Literature at the Federal University of Rio de Janeiro. His book Modernism and Coherence: Four Chapters of a Negative Aesthetics is forthcoming from Duke University Press. 
however, schemata here are far from being a part of our natural constitution, but rather they must be acquired in a painful and coercive social process of learning. It should be emphasized that mainstream schematism is above and beyond individual agency (no evil mastermind here trying to dominate people's brains), for it finds its deepest motivation in competition for the market, even when this is dominated by quasi-monopolies. As for Adorno's own aesthetic agenda to counter mainstream homogenization, its main weapon was experience (in the sense of Erfahrung), a borderline concept/affect that, mediating the concept, was supposed to point beyond it and show in the subject what surpasses it (see Thyen 176-221; Negt 169180). ${ }^{1}$

But for all that mainstream culture is at the same time too rich. It is not only the case that its schemata are multiple, that they are subordinated to history and in close alliance with technological development, as we will see shortly; it is rather that, by their very totalizing nature, they proliferate details. To be sure, these are not in a relationship of tension with the whole they should be parts of, for their character is unredeemably unmotivated and dispensable: in mainstream culture details can be replaced without significant changes in the overall meaning of their texts. But herein lies the problem: how can one interpret something that is just like countless examples of its genre without relying on minutiae, which is what would be most foreign to its nature? In other words: how to read a mainstream text (visual, aural, or otherwise) without transforming contingency into necessity, chance into purpose? This much should be clear: that there is nothing wrong about micrologically focusing on a detail and (virtuosically) turning it into the text's very core and center of being - even by positing it as a textual-unconscious fundamental layer; the problem would still remain that through this operation the object in question ceases to be a mainstream one. From the point of view of the spectator this would be untrue to his or her own empirical, lived experience (now in the sense of the German Erlebnis), reducible in the last instance to the thrill and per se averse to reflection; from that of the thing itself, it would represent the imposition of an artificial break in an unstoppable flux of signs, messages, and stimuli, all of which incessantly tend to extreme self-identity. ${ }^{2}$ Micrology produces the necessary result that from the undifferentiated waves of pseudo-novelty one specimen is withdrawn and endowed with a principum individuationis: interpretation shapes and converts it, inevitably, into a monument.

There are surely ways of bypassing this apparently insurmountable dilemma, perhaps most obviously in the spiritualization of number, whereby mainstream artifacts would be read in huge samples and statistically mapped out so as to show the representativeness of privileged elements through their sheer accumulation and structural iterability. This would make it possible to describe a general mainstream grammar of recurrent features which could in turn be analyzed. (One could think, for instance, about the countless running chases through urban crowds in film. Not one single time does a passer-by stop the criminal/hero to start a fight after being bumped into ....) We will follow here another thread, a more Hegelian one. If mainstream culture poses obstacles to reading (which is indeed completely different from the by now famous resistance to interpretation), it is they themselves that 
should be read. Hegel might very well have termed this a coming-into-consciousness of itself, but he could only have done so because his vision of the world, as we know, was a positive one aimed at a perfect reconciliation with existing reality. It seems more appropriate, for a cultural sphere ultimately ruled by profit and exercising an unheard-of power of standardization, to designate that kind of interpretation that interprets its neutralization as a short-circuit: the strategy whereby one shows that a text's drive against reading is dissolved, in spite of and against itself, once it is properly read.

Even without being exemplary, Red Dragon is representative. Like so many other films it was adapted from a pop novel bearing the same title, and like so many others it deserved a remake. What makes it so interesting is, first of all, the almost unimaginable changes registered in a mere 16 years time, from the first adaptation by Michael Mann in 1986, Manhunter, to Brett Ratner's 2002 Red Dragon. The films and novel belong, of course, to the genre of the detective story, one of the most canonical, together with science fiction, in mainstream culture. It is perhaps precisely because of this "traditional" character that a peculiar logic of the origin could make itself felt in it, making apparent what otherwise would have passed unnoticed: that in mainstream culture reading becomes increasingly equated to evil. Were it not for the latest developments in film (as in Seven or in the other two episodes of the trilogy to which Red Dragon belongs, The Silence of the Lambs and Hannibal), this insight would have remained beyond one's reach. In other words, it is only through the unpredictable progression of history that the new shows itself to have always been there in the old, just waiting to be focused on, whereas if time had passed in a different way, it would never have existed in the first place. ${ }^{3}$ Thus it is that today we are able to notice the utterly paradoxical emergence of interpretation in the origins of the detective story, not only in Edgar Allan Poe, its literary progenitor, but also in early mainstream representatives, such as Sherlock Holmes or Agatha Christie. What is at stake in this case is the contradictory movement allowing reading to become the story's motor, to be placed at the very core of action and plot development, at the same time that it starts to be attached to and associated with evil. This is not denied but rather strengthened by a recent loosening of the genre. Contrary to one of the most fundamental conventions of the detective story, Red Dragon presents the criminal in the middle of the plot, thus doing without the final moment of recognition and disclosure of evil. It is true that this makes the story bend towards the thriller; yet, precisely because the impact of discovery is missing, reading comes to the fore in a much purer way. Devoid of its former telos, the secret, mainstream detective story/thriller is much more straightforward about what is at stake: following a tendency that would only get stronger with time, these narratives feed on that which they are organized to destroy. ${ }^{4}$

There are other important differences at work in this development, however. Former evil was related to a strong form of subjectivity (the criminal as an educated and deranged mastermind), even when, as with the Victorian Doyle, an obsession with pathology could be clearly felt. In the second place, in the late nineteenth and early twentieth centuries the detective's interpretative virtuosity was not rigor- 
ously confined to the decipherment of law-breaking enigmas, but was open to the world: here and there the reader could get scraps of reading applied to everyday life, which thus conferred some meaning to it. ${ }^{5}$ The novelty presented by Red Dragon is a radical exacerbation of this in the complete confinement of interpretation to police activities. The film has as its semantic poles the realm of everyday life, on the one hand, and that of heinous crime, on the other; the detective's work is the element linking the two, for he must read in the former the traces left by the latter. Hermeneutics becomes associated with evil, first of all, because its aim is not the proliferation of meaning, but its own annulment in the harmony of the family. This is not only the sphere where total fulfillment should be found; it is also the space, we are constantly shown, that is properly purged of all ambiguity, a self-centered universe devoid of all troubling signs and which, as such, does not need to (or ought not to) be read. Indeed, the ending of the film is emblematic of this, in the sharpest disagreement with the novel: after all conflict and tension is gone, the nuclear family sails a lonely boat in a deserted sea. This blatant opposition between crime/writing and society/family, here is my claim, is an essential trait of the detective story, one that in fact goes a long way to explain the nature of mainstream culture as a whole in its hostility towards interpretation. ${ }^{6}$

The film tells the story of a pathological serial killer who methodically and ritualistically kills families as wholes - parents, children, and pets. He derives his knowledge from videotapes he obtains from his work in a firm that edits home videos; these, we repeatedly see, portray the epitome of family happiness, with all nuclear members co-acting in perfect harmony (again, pets included). In order to properly fight the psychopath, the FBI must appeal to a former agent, Will Graham (Edward Norton), who had to retire after having been severely wounded in the process of capturing the terrible Dr. Hannibal Lecter (Anthony Hopkins), convicted of serial-killing cannibalism. What is special about Graham is his ability to figure out what passes in the criminal's mind, in a procedure that could very well be called mimetic. By reconstituting or re-experiencing the killer's original thoughts and feelings, Graham enters into an overwhelming dialogistic monologue, e.g.: "You took your gloves off, didn't you, you son of a bitch! You took your gloves off, you touched her with your bare hand and then you wiped her down." The faculty he excels at is acknowledged by both sides; first by Lecter himself, who says that Graham has something "akin to artistic imagination": "You are able to assume the point of view of other people, even though it might scare or sicken you. It's a troubling gift, I should think." This is repeated by his former boss, officer Jack Crawford (Harvey Keitel): "I have technicians that can examine evidence, but you got that other thing, imagination, projection, whatever."

The differences in register between these two descriptions are telling. But even more interesting is the kind of work they allude to. For if one joins to this openness and spontaneity the other side of Graham's job, the rigorous logical work of linking clues and organizing them into a coherent whole, it is then possible to get very close to a characterization of the artist's practice in its most emphatic sense as the conjunction in tension between mimesis and rationality, impulse and concept. ${ }^{7}$ As for the affects involved in his interpretative acts, they are far from simple. On the 
one hand, his ability to glare into the machinations of evil is a source of acute pain; on the other, however, the absolute devotion triggered by the case's riddles, as well as the enthusiasm following each step of its resolution, clearly suggest that some kind of pleasure is at stake in the interpretative practice that lies far beyond its immediate justification, which sounds more like a feeble rationalization that reading here is saving lives. But it is not that important to know if the disturbing element is the pure mental suffering caused by the glimpse of evil or the perhaps more troubling insight that evil could be inextricable from pleasure. For the fact remains that this is a place one should want to escape, finding comfort in the peace and authenticity of the family.

However, it is when we turn to the psychopath Francis Dolarhyde (Ralph Fiennes), also called "The Tooth Fairy," that the most revealing features emerge in the transition from Manhunter to Red Dragon. What in 2002 becomes clear is that the enemy writes, and in many different ways. There is, first of all, the diary he keeps, with hundreds of hand-written and illustrated pages. In opposition to the immense mechanical/electronic social apparatuses of decipherment, to which we will turn shortly, the diary is representative of the letter in its calligraphic form, which betokens less of a unique subjectivity than the manifestation of strong desire. ${ }^{8}$ Then, it is impossible not to take into account the criminal's awe-inspiring tattoo on his back representing the dragon of the title (conveniently ignored in the first adaptation). Here one witnesses a kind of writing on and of the body, adding meaning to and changing it. It is no wonder that this production of excess takes shape through the visionary figure of William Blake, who, as a conspicuous creator of worlds, could very well be seen in this context as a synecdoche for literature as a whole. Indeed, Dolarhyde's reaction to Blake's painting, in a scene where he is about to eat it, would not surprise admirers of the poet:

There it was. The Great Red Dragon and the Woman Clothed with the Sun-the Man-Dragon rampant over the prostrate pleading woman caught in a coil of his tail.

It was small all right, but it was powerful. Stunning. The best reproductions didn't do justice to the details and the colors.

Dolarhyde saw it clear, saw it all in an instant-Blake's handwriting on the borders, two brown spots at the right edge of the paper. It seized him hard. It was too much ... the colors were so much stronger. (Harris 383)

The art-lover and the freak, the sociopath, turn out to be united in their epiphanic contemplation of visionary beauty.

In the third place, one should mention Dolarhyde's attraction to mirrors, that most traditional metaphor for writing, and his placing of small pieces of reflecting glass in his victims' eyes. This procedure is too easily dismissed by Graham and Lecter as a way of creating an audience, for what they forget is that while Dolarhyde is the Red Dragon he is not himself. Indeed, if one adds to this "transformation" of the body (named as such in both book and films) the explicit theme of Becoming (capitalized in the book), it is difficult not to notice here the echoes of much of poststructuralist theory: the questioning of the body's limits, the fluidity of identity, the 
relationship between writing and pain, the structure of jouissance. This coincidence is revealing of an overall social trend that ultimately gives birth to analogies linking philosophical critique (the regulated, "normal" body as an instance of control and discipline) and the internal logic of the film industry. Since in order to make money the latter needs to present the old under the guise of the new, which is so well translated by the expression "to create a sensation," it is obliged to invest in elements that increasingly advertise themselves as different while being basically the same. Thus the "more" progression: more action, more speed, more violence. This increasing bombardment of stimuli on the nervous apparatus has reached such a level that, in spite of the overall impetus of films, they end up questioning the unity of the body and the limits of violence, as well as challenging the very meaning of pathology (see Türcke 71-77).

Herein lies a contradiction typical of extreme mainstream culture in film, which cannot but be ambitious (the amount of money invested in it requires it) but has to contain (in both senses of "checking" and "enclosing") the potential it is forced to make use of. In Red Dragon this happens by means of the utterly impoverishing psychological proto-narrative involving the main evil character, a boy, we are shown, who was raised by a domineering grandmother and whose memories still haunt him. But if this subtext fails to completely mediate an abused childhood with the posthuman Red Dragon, it serves the purpose of inserting the family space as both the origin of the problem and the realm of its possible solution. Reba McClane, a blind woman who works with Dolarhyde, is not shocked by his looks and eccentric behavior; she represents an equal, someone who also has a "disability" but who manages to function well in society. She is a source of hope inasmuch as with her the Red Dragon's evil could be tamed by the formation of a nuclear family. If only Dolarhyde had not misrepresented the relationship between Reba and Ralph Mandy, another coworker, so the film makes us wonder, then there would be a way out for him, a passage from the dark and dangerous world of writing/reading to that of the lack of ambiguity in the conflict-free home.

Mediating between the hero and villain is the third pivotal element of the film: the police and the FBI. It is Crawford himself who takes Graham away from what we are led to see as paradise, and it is the FBI and the police who provide the material support needed for him to read and reconstitute what passes through Dolarhyde's mind. What they obviously represent is a social apparatus of repression, one which, again, evinces the most astounding development from the stone-age computers in Manhunter to the up-to-date digitalized network of identification and decoding. It would be tempting to posit an en abîme structure in this case, whereby the technological development undergone by the police would be a miniature of, and would stand for, the film itself in relation to its precursor. But whether or not one relies on this clue, the parallels between the police and mainstream film are worth paying attention to, for both are socially prominent and aspire to be ubiquitous. (The camera indeed has come to perform both roles of universal instrument of surveillance and fundamental means of representation, as the verb "to shoot" and its derivatives attest.) Furthermore, there is something revealing in the kind of opulence at stake here, not only in the habitually exorbitant Hollywood film budget (by 
now an important part of any mainstream film advertisement campaign) but also in the amount of resources available to repressive apparatuses. Perhaps one has to live in a Third World country, as I do, to be able to recuperate something of the amazement coming from the disproportionality between that one individual, Dolarhyde, and the State's inextinguishable resources. From the point of view of its employees (state policemen, FBI agents, all sorts of technicians), an interesting dialectics takes place, whereby the agents of repression renounce the division between their private lives and their work in order to guarantee that this division remain absolute. As for material resources, their total deployment of means is redolent of the purest totalitarian fantasy: in a film where realism seems only to be left aside in the murderer's pathological, delirious transgression, one might very well ask if this apparently infinite availability - of helicopters, 24-hour personnel, computers, and so forth - is not somehow fanciful, even in the case of a famous serial killer deserving abundant news coverage. The suspicion may very well arise, that is, that in this perfect working of the repressive machine (no one on vacation here, no single computer breakdown, no one using an equipment when it is needed, no space for a lazy "let's-do-it-tomorrow" attitude) a social truth is manifested: that writing/reading is dangerous and that to combat it there are no limits to the State apparatuses of counter-reading.

One of the most important methodological findings developed by structuralism was to analyze texts as though they were single sentences. Later on, this procedure, which aspired to science, was denounced for what it really was: a metaphor. Still, if one wants to make use of it here, adding a little more linguistics, it could be said that, as a single proposition, Red Dragon is in the imperative mode and its illocutionary force is an appeal for the spectator to be thrilled. As for the propositional content, it would be something like "reading is evil" (or worse, vice-versa: "evil is reading"), which can only lead to the logical inference: "one ought not to read." This injunction is at the same time the strongest and the weakest. The strongest, because it pervades society in the most forceful and comprehensive way, making itself felt virtually everywhere; in its generality, it corresponds to a long circuit of non-reading. It is indeed a precondition for today's total commodification of life, as has become most obvious in the incredible consolidation of corporate logos. These are decoded, not interpreted; perceived, they undergo a process of identification leaving no residue behind. But the interpellation not to read is also the weakest, because all it takes to dissolve it is to read it.

\section{Notes}

The author wishes to thank Stephan Schoenholtz for his generous comments.

${ }^{1}$ Negt argues that experience is what mediates Adorno's aesthetic and sociological writings; as such it is the key concept (Schlüsselbegriff) in his philosophy.

${ }^{2}$ For the philosophical implications of the thrill and sensation, see Türcke.

${ }^{3}$ This logic of the origin is well described by Alexander García Düttmann in Das Gedächtnis des Denkens. 
${ }^{4}$ This is but a rephrasing of Fredric Jameson's influential idea about the dependence of reification on Utopia in "Reification and Utopia in Mass Culture."

${ }^{5}$ It would be interesting to posit that the world's a priori readability in the detective story corresponds to the survival, however dim or even degenerated, of that meaningful and closed totality the young Lukács saw in ancient Greece under the form of the epic (see 29$55)$.

${ }^{6}$ In fact, a vision of Utopia comes to the fore as the negative of this formulation: the sublation (in the sense of Aufhebung, of maintaining and overcoming) of mainstream ubiquity through the boundless unfettering of reading and its expansion to all pores of life.

${ }^{7}$ Perhaps the best place to verify this is in Adorno's chapter on Schoenberg in Philosophy of Modern Music (29-134).

${ }^{8}$ That there is something disturbing about writing here is attested by the fact that the diary was chosen to be the center of the film's introduction, which is the part supposed to excite. A good way to measure the success of a mainstream piece is to ask if it is worthy of its introduction. Very few are.

\section{Works Cited}

Adorno, Theodor. Philosophy of Modern Music. Trans. Anne G. Mitchell and Wesley V. Bloomster. London: Sheed \& Ward, 1994.

- . "The Schema of Mass Culture." The Culture Industry: Selected Essays on Mass Culture. Ed. J. M. Bernstein. London: Routledge, 1991. 61-97.

Düttmann, Alexander García. Das Gedächtnis des Denkens: Versuch über Heidegger und Adorno. Frankfurt: Suhrkamp, 1991.

Harris, Thomas. Red Dragon. 1981. New York: Dell, 2002.

Jameson, Fredric. "Reification and Utopia in Mass Culture." Signatures of the Visible. London: Routledge, 1990.9-34.

Lukács, György. The Theory of the Novel: A Historico-Philosophical Essay on the Forms of Great Epic Literature. Trans. Anna Bostock. Cambridge, MA: MIT Press, 1971.

Manhunter. Dir. Michael Mann. Perf. William Petersen and Tom Noonan. De Laurentiis, 1986.

Negt, Oskar. "Adornos Begriff der Erfahrung." Impuls und Negativität: Ethik und Ästhetik bei Adorno. Ed. Gerhard Schweppenhäuser and Mirko Wischke. Hamburg: Argument, 1995. 169-180.

Red Dragon. Dir. Brett Ratner. Perf. Edward Norton, Anthony Hopkins, and Ralph Fiennes. Universal, 2002.

Thyen, Anke. Negative Dialektik und Erfahrung: Zur Rationalität des Nichtidentischen bei Adorno. Frankfurt: Suhrkamp, 1989.

Türcke, Christoph. Erregte Gesellschaft: Philosophie der Sensation. München: Beck, 2002. 